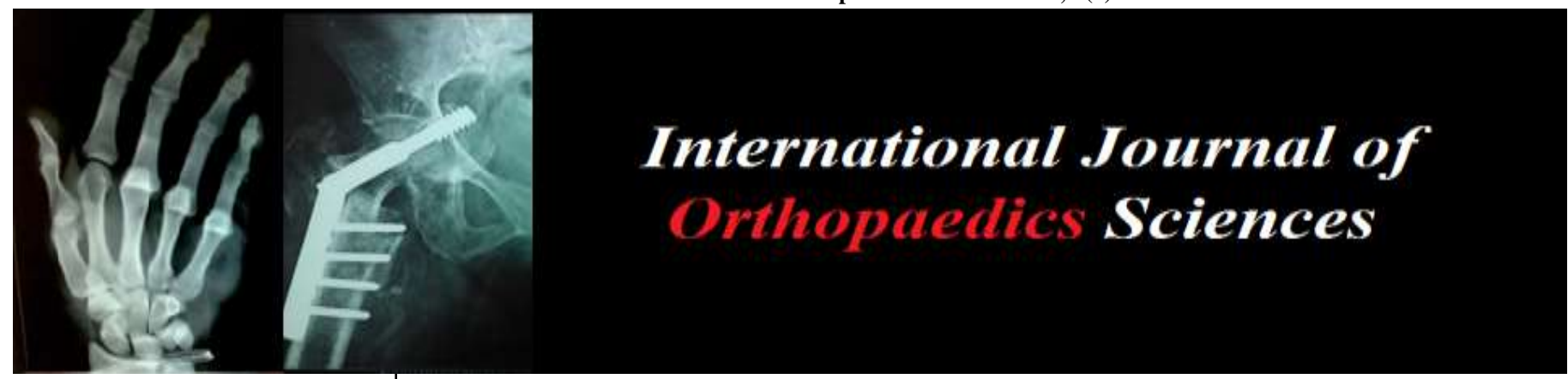

E-ISSN: 2395-1958

P-ISSN: 2706-6630

IJOS 2021; 7(1): 272-274

(C) $2021 \mathrm{IJOS}$

www.orthopaper.com

Received: 22-10-2020

Accepted: 02-12-2020

Dr. Mahendhira Varman Associate Professor,

Department of Orthopaedics, Shri Sathya Sai Medical College

\& Research Institute

Ammapettai, Chengalpattu,

Tamil Nadu, India

Dr. F Abdul Khader

Professor \& HOD,

Department of Orthopaedics,

Shri Sathya Sai Medical College

\& Research Institute,

Ammapettai, Chengalpattu,

Tamil Nadu, India

Dr. Reddy Jyothi Krishna

Final Year Postgraduate

Department of Orthopaedics,

Shri Sathya Sai Medical College

\& Research Institute,

Ammapettai, Chengalpattu,

Tamil Nadu, India
Corresponding Author: Dr. F Abdul Khader Professor \& HOD,

Department of Orthopaedics, Shri Sathya Sai Medical College \& Research Institute,

Ammapettai, Chengalpattu,

Tamil Nadu, India

\section{Case report: THR (total hip replacement) for primary ankylosing spondylitis (as) hip in young age}

\author{
Dr. Mahendhira Varman J, Dr. F Abdul Khader and Dr. Reddy Jyothi \\ Krishna
}

DOI: https://doi.org/10.22271/ortho.2021.v7.i1e.2496

\section{Abstract}

In systemic inflammatory arthropathies, Ankylosing spondylitis (AS) is a major disease whose pathogenesis is not understood completely, but positive involvement of HLA-B27 markers is observed. It effects, hip in 30-50\% patients with systemic inflammatory arthropathies. Primary THA (total hip arthroplasty) has shown long-term betterment of hip function in patients with AS (ankylosing spondylitis).

Keywords: Ankylosing spondylitis, total hip arthroplasty

\section{Introduction}

The bilateral coxofemoral ankylosing spondylitis (AS) leading to osseous ankylosis is more common. This osseous ankylosis leads to articular stiffness primarily at hip, and surrounding articulations. Several points has been disrupted for management of AS (ankylosing spondylitis) patients because of relative prevalence of this disease is the main reason. ASAS group criteria has provided standard evaluation for different modalities of treatment in patients with AS (ankylosing spondylitis). The base drugs for treatment are still Non-steroidal NSAIDs. Cyclooxygenase type II has shown same results as NSAIDs in recent studies. Thalidomide has shown better results in patients with peripheral articular manifestations \& axial disease refractory to NSAIDs. But the mobility $\&$ indolence for which the patient wished is achieved by THA (total hip arthroplasty. In human body, hip provides major weight bearing $\&$ wide range of movements, any damage to it causes physical \& emotional suffering to patient. Any delay in diagnosis leads to long-term complications. We reported a case with unique history leading to diagnosis and management.

\section{Case report}

A 24 year old male came to the opd with a chief complaints of pain in bilateral hip (R>L) from 2 years. Pain started in the Right hip, 2 years back which is squeezing type of pain and nonradiating with no history of fever, weight loss, cough. Pain is more during night time and patient is complaining of night cramps. Pain is aggravating on walking and relieved on taking rest. The pain started aggravating with time and slowly patient started restriction of range of movements in the right hip, shoulder and patient was unable to squat and sit on floor with legs folded. Patient went to near by private hospital initially they treated him symptomatically. Up on taking detailed history, Patients brother had a history of T.B attack in patients childhood so the doctors suspected for T.B hip with lungs as the primary foci and started him on ATT (antitubercular treatment) for 1 year still the pain is persistent and hip stiffness is progressing, so patient came for further management to our hospital.

Patient underwent MRI 2 years back which showed marrow edema at acetabulum and femur head with mild synovial thickening \& effusion and gamma interferon positive so he was started on ATT and treated for T.B hip by other doctors.

After admitting in our hospital, we did all routine pre op investigation along which we have send for ESR \& CRP. Which came as non-reactive CRP \& mildly elevated ESR. We have repeated MRI \& send HLAB-27 antigen test. 
MRI has shown bilateral asymmetric arthritis (R>L) with significant degenerative changes on right side with ankylosis of bilateral sacroiliac joints \& edema in right ischial tuberosity. HLAB-27 came positive. Since patient had a contact with T.B to rule out T.B we have done mantox test, sputum for AFB, gene expert which all came negative. We have done PET scan which has shown degenerative arthritic changes in bilateral hip joints $(\mathrm{R}>\mathrm{L})$, bilateral facet joints of L2-L3, L3-L4 vertebrae, bilateral sterno-clavicular joints and shoulder joints. Bilateral sacroiliac joint ankylosis with no significant 99mTc uptake, no abnormal 99mTc MDP uptake in any small and larger joints of the body in blood flow, pool and in delayed static phase. Finally patient was diagnosed as primary AS (ankylosis spondylitis) of hip. Patient was advised for bilateral THA as a staged procedure with right hip operated first later on the left hip. With all the consent and explaing of disease progression, right hip cemented THA (total hip arthroplasty) under regional anesthesia, with modified Harding approach was done. Patient was stable post operatively and regular physiotherapy was done for right hip. Later after 2 years left hip cemented THA was done under same conditions and same approach as right hip and regular physiotherapy was given to both hips with spine strengthing exercise. Patient was happy with the out-come and he was able to do day to day activities with improved range of movements at the Hip.

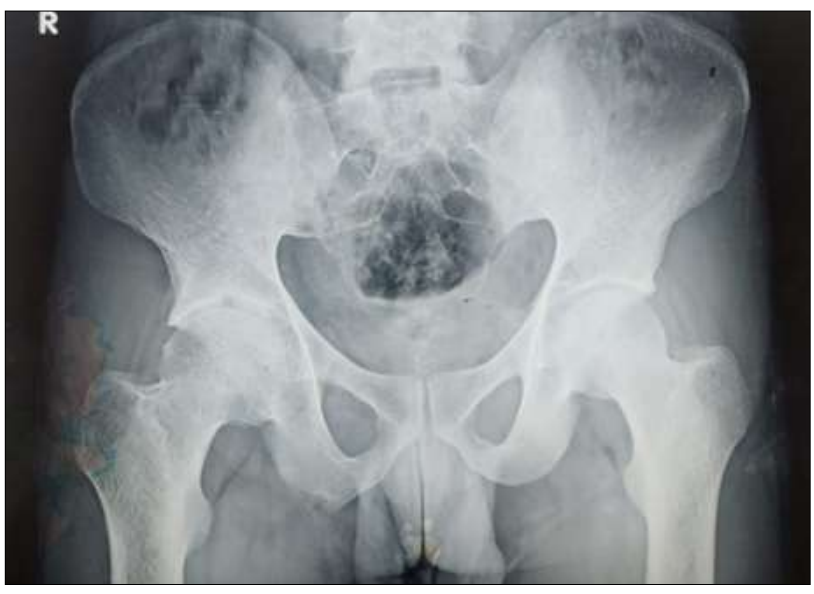

Fig 1: Initial x ray of patient

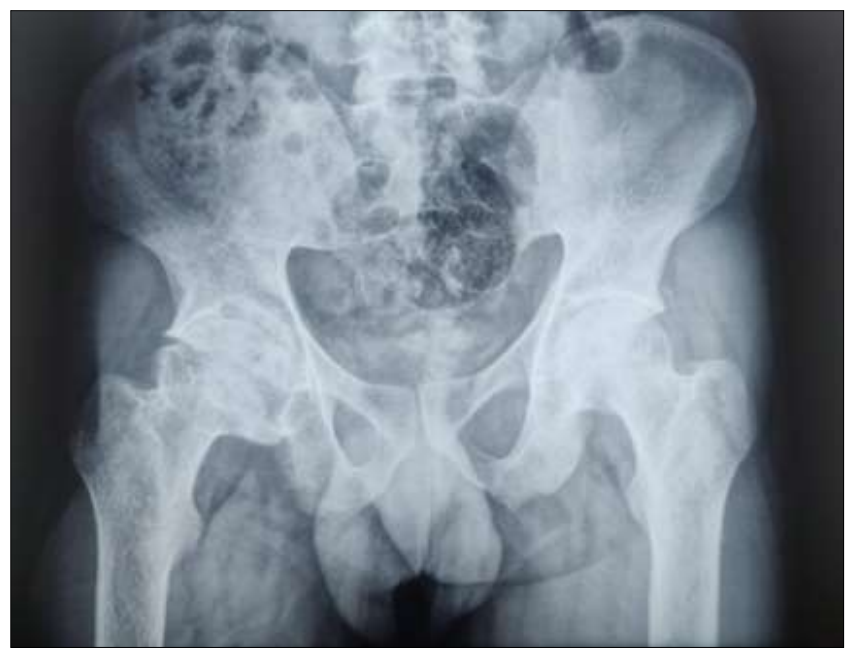

Fig 2: X-ray after 2 years

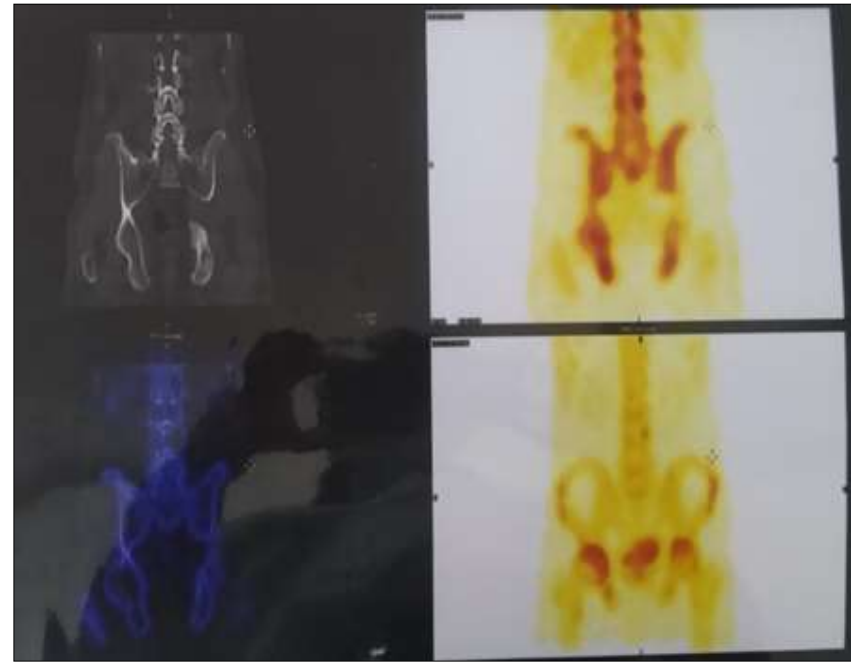

Fig 3: PET SCAN report

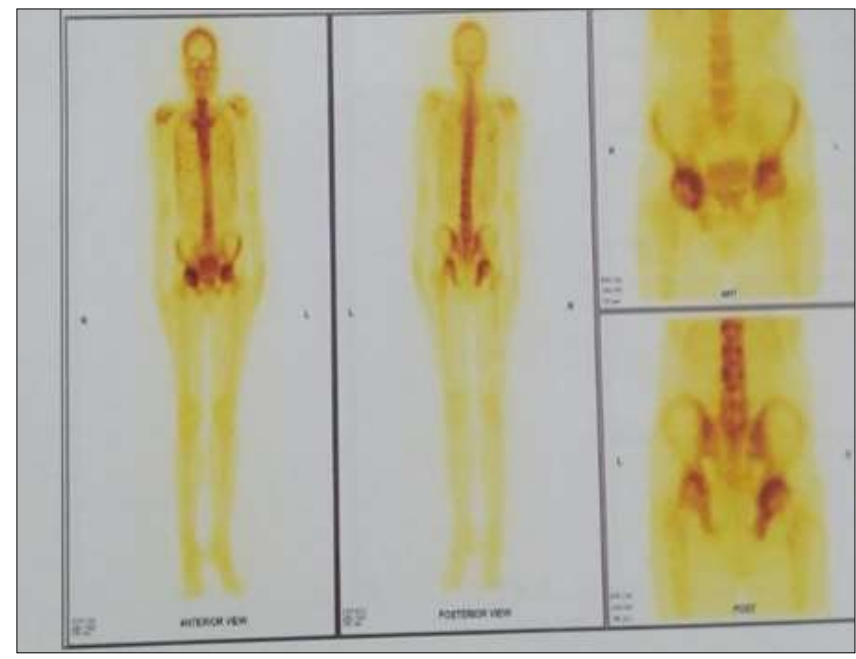

Fig 4: Full body PET scan report

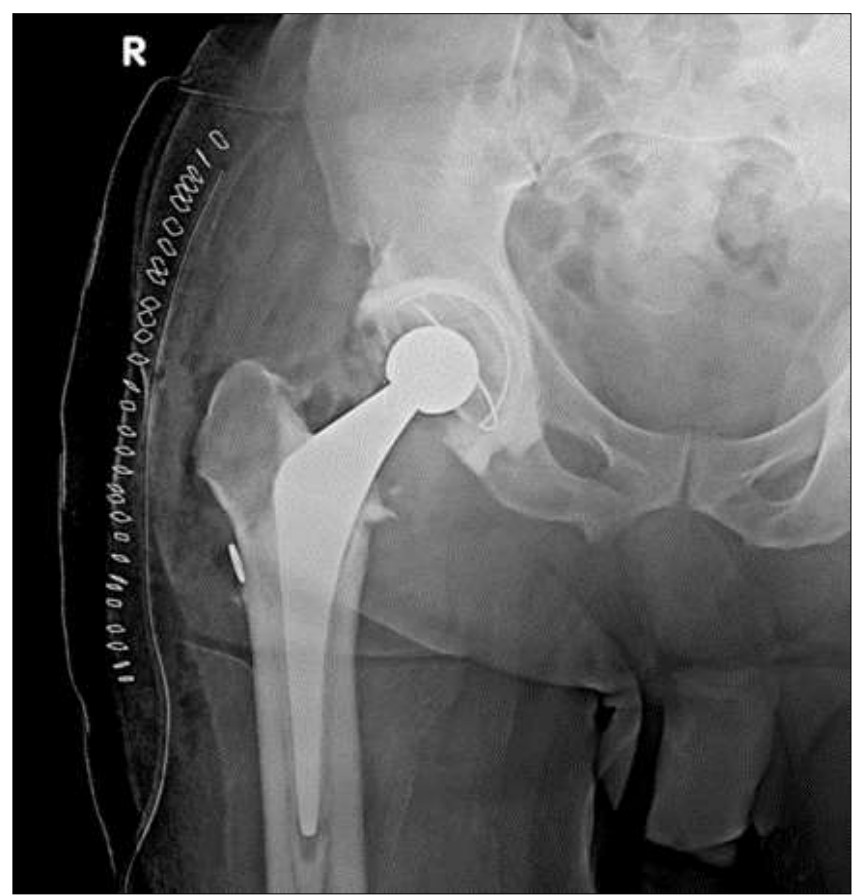

Fig 5: Right side THR 


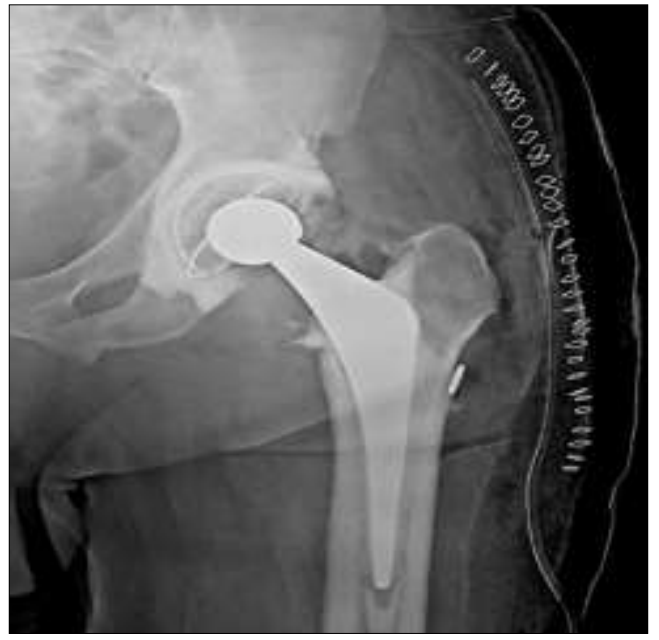

Fig 6: Left Side THR

\section{Discussion}

In AS (ankylosing spondylitis) symptoms appear at very young age. Early diagnosis and management provide benefit to patient post-operatively in daily activities and increase the life span of surgery done. The patients with AS (ankylosing spondylitis) should be operated as early as possible to avoid stiffness rapidly or ankylosis of joint in faulty position and avoid crippling deformities.

In our case, the age of patient we operated was 24 years, in other studies the average age was

Table 1: Average age in various studies

\begin{tabular}{|c|c|c|}
\hline Study & Average Age & Study Populatiuon \\
\hline Cato $^{[1]}$ & 31 years & 18 \\
\hline Brinker $^{[2]}$ & 35 years & 20 \\
\hline Tang $^{[3]}$ & 38.9 years & 95 \\
\hline Joshi $^{[4]}$ & 47 years & 181 \\
\hline
\end{tabular}

Most of the authors achieved encouraging results in young age patients, with them as guides we started treating and operated our patient as early as possible. AS (ankylosing spondylitis is most common in male group and patient is a male and other studies which showed similar results were

Table 2: Sex predominance in various studies

\begin{tabular}{|c|c|}
\hline Study author & \% of male predominance \\
\hline Bisla $^{[5]}$ & $60.8 \%$ \\
\hline Joshi $^{[4]}$ & $68 \%$ \\
\hline Tang $^{[3]}$ & $96 \%$ \\
\hline
\end{tabular}

Anesthetic technique for THA (total hip arthroplasty) is the major concern, the most preferable was regional anesthesia over general anesthesia because after general anesthesia stiffness of jaw, spinal ankylosis provide difficulty for resuscitation [6]. Because of this our patient was operated under regional anesthesia. We have used modified Harding approach as per surgeons choice, various approaches used in different surgeries are

Table 3: Type of approach in various studies

\begin{tabular}{|c|c|c|}
\hline Study Name & Study population & Type of approach \\
\hline Joshi $^{[4]}$ & 181 THA & Trochanterotomy \\
\hline Brinker $^{[2]}$ & 20 THA & Harding \\
\hline Tang $^{[3]}$ & 95 THA & Posterolateral approach \\
\hline Caton $^{[1]}$ & 18 THA & Posterolateral approach \\
\hline
\end{tabular}

The choice of implant until now is unclear. For our patient we used cemented THA for best results \& primary stability. In study done by Tang ${ }^{[3]}$ cemented prosthesis at the end of 5 years have $100 \%$ longevity while at the end of 10 years it has $96.8 \%$ longevity. While, uncemented has $95.5 \%$ at end of 5 years \& fell to $63.6 \%$ at end of 10 years. After the surgery our patient has reduced pain and increased range of movements around the hip joint.

\section{Conclusion}

The future crippling and co existing with AS (ankylosing spondylitis) has changed in patients after TKA. The results were brilliant short-term and mid-term but ignoring the wear $\&$ tear of the implant with increased daily activity was a big mistake. For this we advise better pre-operative planning and careful extensive physiotherapy for providing longevity of implants.

\section{References}

1. Caton J, Courpied JP, Ferreira A et al. Total Hip Arthroplasty. 4th Symposium Charnley International Lyon, Lyon, 2004, 130-135, 77-78.

2. Brinker M, Rosenberg A, Cox D et al. Primary Noncemented Total Hip Arthroplasty in Patients with An- kylosing Spondylitis: Clinical and Radiographic Results at an Average Follow-Up Period of 6 Years. The Journal of Arthroplasty 1996;11:802-812. http://dx.doi.org/10.1016/S0883-5403(96)80180-X

3. Tang WM, Chice KY. Primary Total Hip Arthroplastiy in Patients with Ankylosing Spondylitis. The Journal of Arthroplasty 2000;15:52-58. http://dx.doi.org/10.1016/S0883-5403(00)91155-0

4. Joshi B, Markovic L, Hardinge $\mathrm{K}$ et al. Total Hip Arthroplasty in Ankylosing Spondylitis: An Analysis of 181 Hips. The Journal of Arthroplasty 2002;17:427-433. http://dx.doi.org/10.1054/arth.2002.32170

5. Bisla R, Ranawat C, Inglis A. Total Hip Replacement in Patients with ankylosing spondylitis with In-volvement of the Hip. The Journal of Bone and Joint Surgery (American Volume) 1976;58:233-238.

6. Chen YQ, Ji ZY, Sun FX et al. Total Hip Arthroplasty for the Treatment of Ankylosing Spondylitis in 11 Cases. Journal of Clinical Rehabilitative Tissue Engineering Research 2008;12:48.

7. d'Aubigné M. Quotation Calculated by the Function of the Hip. Revue de Chirurgie Orthopédique et Réparatrice de l'Appareil Moteur 1997;56:481-486.

8. Sochart DH, Porter ML. The Long-Term Results of Charnley Low-Friction Arthroplasty in Young pa-tients Who Have Congenital Dislocation, Degenerative Osteoarthrosis, or Rheumatoid Arthritis. The Journal of Bo and Joint Surgery (American Volume) 1997;79:15991617.

9. Kilgus DJ, Namba RS, Gorek JE et al. Total Hip Replacement for Who Have Ankylosing Spondylitis. The Importance of the Training of Heterotopic Bone and of the Durability of Fixation of Cemented Components. The Journal of Bone and Joint Surgery (American Volume) 1990;72:834-839.

10. Williams E, Taylor AR, Arden GP et al. Arthroplasty of the Hip in Ankylosing Spondylitis. The Journal of Bone and Joint Surgery (American Volume) 1977;59:393-397.

11. Walker LG, Cement B. Total Hip Arthroplasty in Ankylosing Spondylitis. Clinical Orthopaedics and Related Research 1991;262:198-204.

12. Vastel L, Kerboull L, Dejean $\mathrm{O}$ et al. Prevention of Heterotopic Ossification in Hip Arthroplasty. The Influence of the Duration of Treatment. International Orthopaedics 1999;23:107-110. 